\title{
Synchromodal Transportation Planning using Travel Time Information*
}

\author{
Hannah Yee ${ }^{\mathrm{a}}$, Joren Gijsbrechts ${ }^{\mathrm{b}}$, Robert Boute ${ }^{\mathrm{a}, \mathrm{c}}$ \\ ${ }^{a}$ Faculty of Economics and Business, KU Leuven, Belgium \\ ${ }^{b}$ Católica Lisbon School of Business 86 Economics, Lisbon \\ ${ }^{c}$ Vlerick Business School, Belgium
}

\begin{abstract}
Synchromodal transportation planning is defined by the possibility to re-route shipments to alternative transportation modes at intermediate terminals based on real-time information about the shipment in transit. We present a synchromodal decision support model to determine the optimal modal choice for a single shipment in a multimodal network that is characterized by stochastic travel times. The model is formulated as a Markov decision process and allows adaptations to the modal choice based on real-time information on the travel time. Our formulation trades off transportation and late delivery penalty costs, and captures the value of synchromodal planning. We demonstrate the use of our model in a numerical case study, where we evaluate synchromodal against static intermodal transportation planning. The latter does not allow real-time adjustments to the modal choice. Compared to intermodality, synchromodal planning has most value when the penalty for late delivery is high and transportation services are more frequent.

Keywords: synchromodality, Physical Internet, stochastic travel times, adaptive decision-making, Markov decision process, real-time information
\end{abstract}

\section{Introduction}

The current ecological footprint of the logistics industry necessitates more sustainable operations. In 2015 , the transportation sector represented $18 \%$ of all man-made $\mathrm{CO}_{2}$ emissions, with freight transportation accounting for almost half of these emissions (International Transport Forum, 2017). The organisation for 5 economic co-operation and development (OECD) projects a $60 \%$ increase in transportation emissions by the year 2050 if current practices are pursued, primarily driven by freight transportation. To limit further environmental damage, the European Commission is determined to transition to a low carbon economy by 2050. The roadmap towards that target enforces the transportation sector to cut its emissions by at least $60 \%$ (European Commission, 2011).

In order to transition towards a more efficient use of transportation facilities, thereby reducing carbon emissions in freight transportation, Montreuil (2011) introduced the Physical Internet concept. The Physical Internet, inspired by the digital internet, targets a more connected global logistics system by integrating separate logistics networks and services into one hyperconnected network, grounded on both physical and

\footnotetext{
* To appear in Computer in Industry
} 
digital interconnectivity (Montreuil et al. 2012). Shipping freight over an interconnected network requires switching between, and integrating with, different transportation modes to exploit the benefits of each modal choice. This raises an opportunity to induce a shift from road to less carbon-intensive transportation modes, such as rail and inland waterways, and aligns with one of the key goals of the Transport 2050 plan, targeting a $50 \%$ shift from road towards rail and inland waterways by 2050 (European Commission, 2011).

To date, road transportation still prevails because of its flexibility in terms of availability and resilience to disturbances or delays (Tavasszy et al., 2015, Meers et al., 2017), despite that rail and inland waterways may be available at a lower unit transportation cost, provided sufficient volume. Intermodal transportation presents a first step to achieve a shift towards alternative transportation modes, combining different modes along the shipping route (Reis, 2015). The implementation of intermodality, however, remains modest because of its limited flexibility. Under intermodal transportation planning, the transportation modes of the various route segments are determined at the start of the shipment and cannot be altered along the route based on real-time information. In order to encourage a further modal shift and promote sustainable transportation modes, synchromodality has been introduced to make intermodal transportation more dynamic, flexible and acceptable. Synchromodal transportation planning is defined by the use of multiple modalities with the option to switch between transportation modes at intermediate hubs to increase flexibility (Tavasszy et al. 2010). The integration of different modalities allows the combination of both speed and cost benefits of each transportation mode (Tavasszy et al. 2015). This integration of logistics services makes synchromodality a cornerstone of the Physical Internet (ALICE, 2014).

The innovative aspect of synchromodal planning is that modal choice decisions can be made based on real-time information about the transportation network and the orders in transit. In other words, in contrast to intermodal planning, the transportation modes are not fixed in advance but can be adapted to real-time information updates. Real-time adaptation provides more planning flexibility, which facilitates mitigation of disturbances in the network. This adaptability allows synchromodal transportation planning to be more responsive compared to intermodal planning, while meeting the service requirements for timely delivery.

To incorporate real-time information about the transportation network, synchromodal planning relies on digital connectivity. It digitally traces the physical freight flows in the network, a prerequisite for successful synchromodal planning (Giusti et al., 2019b; Ambra et al., 2019b). In this paper we will demonstrate how real-time updates on the travel time duration can be taken into account in a multimodal network. This is valuable as transportation services are inherently exposed to stochastic travel times. Rail transportation services, for instance, can result in occasional delays, or road transportation can move faster than expected due to lower than expected traffic congestions. Traceability makes it possible to track orders in transit and have accurate, real-time information on the travel times (Giusti et al., 2019b). Our synchromodal planning model exploits this real-time information by determining whether a shipment should switch to a faster mode in case of delays, or to a slower mode when sufficient time is still available for a timely delivery and less expensive, more sustainable options are favorable. The physical and digital interconnectivity increases the 
flexibility of logistics services, thereby enabling the Physical Internet (Ambra et al. 2019b).

In this paper we present a model that makes use of real-time travel information updates to determine the optimal, cost-minimizing transportation mode choice. We investigate the value of the use of such real-time information updates compared to static intermodal transportation planning, where the transportation mode choice cannot be adapted based on the effective travel time durations.

\section{Literature review}

We review the recent literature on synchromodal planning models and show how our model contributes to the current state of the art. Transportation models can be classified based on their planning horizon Crainic \& Laporte, 1997). General and comprehensive overviews of synchromodal transportation models at different planning horizons can be found in SteadieSeifi et al. (2014), van Riessen et al. (2015a) and Ambra et al. 60 (2019b).

The tactical planning level concerns a medium-term horizon and deals with service network design, determining the selection and frequency of modality services in a network, as studied by van Riessen et al. (2015b) and Mes \& Iacob (2016). Within service design, operational service schedules can be constructed by selecting the appropriate transportation services, taking their availabilities into account with respect to the delivery time requirements (see for instance Behdani et al., 2014). These models focus on the flexible integration of modalities in the transportation network, providing an integrated multimodal network in which a synchromodal transportation planning model can operate.

Operational, short-term planning models operate in a dynamic environment and decisions are adjusted based on real-time information that becomes available over time. In what follows we restrict our attention to studies at the operational level, as they are most applicable to our work. More specifically, we focus on the timing of the operational synchromodal decisions and the type of real-time information taken into account.

van Riessen et al. (2015c) develop a synchromodal planning model that takes service disturbances into account, such as an early or late service departure or a service cancellation, and include the possibility to re-route at intermediate terminals in case of a disturbance. In their work, they construct the transportation planning for one week and re-optimize these decisions based on real-time information on disturbances. Li et al. (2015) deal with disturbances in transportation demand that impact the container availability in the network, as well as traffic conditions that influence the travel time. They cope with these disturbances by using an estimate of their future values, which are updated periodically. Their model re-optimizes the intermodal container flow given the updated estimate values of demand and traffic conditions. Ambra et al. (2019a) present a synchromodal simulation model to react to several types of disturbances on transportation services, which occur with a given probability. Whenever a disturbance arises, the model evaluates potential re-routing or switching to another transportation mode based on a simulation analysis. This approach of re-optimizing in response to deviations from the transportation plan is also employed in the SYNCHRO-NET platform (Giusti et al. 2019a), where real-time data about deviating events trigger re-optimization to find 
85 a new solution that meets the transportation requirements. These works deal with disturbances and delays through a reactive approach, as they assume execution of the shipment per the initial transportation plan and await the occurrence of a deviation before adapting their planning.

Dong et al. (2018) present a synchromodal planning model that takes both transportation and inventory costs at the destination into account. Their stochastic inventory model allocates freight to two parallel transportation modes, namely road and intermodal rail, to ship freight from origin (plant) to destination (distribution center) with the objective to minimize supply chain costs. A constant order is shipped by intermodal rail, while road ships a variable volume every time period to cope with the real-time volatility in demand. Lemmens et al. (2019) extend their model by including the possibility to switch transportation modes at an intermediate terminal along the origin-destination route. This allows slowing down orders by real-time inventory level at the destination upon arrival at the terminal. In their model, it is the inventory level that determines the urgency of the replenishment, which affects the need to speed up or slow down the order in transit.

Pérez Rivera \& Mes (2016, 2017, 2019) study synchromodal planning by means of Markov decision process (MDP) models. This modelling framework has been commonly used to solve sequential decision-making problems in different settings that are subject to uncertainty. The models in Pérez Rivera \& Mes (2016) and Pérez Rivera \& Mes (2017) focus on the consolidation of freight orders. Pérez Rivera \& Mes (2019) use the model of Pérez Rivera \& Mes (2017) to optimize a scheduling problem that integrates long-haul transport with drayage operations.

The work of Pérez Rivera \& Mes (2017) is most related to our problem setting. The difference between our model and theirs, however, is in the research objective and its underlying model assumptions. The key objective of our paper is to study the impact of stochastic travel times and real-time travel time updates on synchromodal transportation planning. Pérez Rivera \& Mes (2017), in contrast, study consolidation decisions of new orders that arrive stochastically in the near future. In other words, the uncertainty in their model is in the arrival of new orders, whereas travel times are assumed to be deterministic. The setup of their MDP is thus different from ours. Amongst others, this translates into an important difference in the state transition dynamics. In their model, the stochasticity in state transitions stems from the stochastic arrivals of new orders, whereas the state transitions in our model depend on the stochastic travel times. The latter depend on the chosen transportation mode.

A second distinction is in the objective function. In Pérez Rivera \& Mes (2017), a setup cost is included per transportation service, independent of the number of freight units shipped on that service, in addition to a variable profit per freight unit. The objective is thus to exploit consolidation opportunities, thereby minimizing total setup costs. In their optimization they anticipate the impact of these decisions on future states in which new orders arrive. The model presented in our article, in contrast, will not focus on consolidation. We focus on the impact of stochastic travel times, thereby including a penalty cost for late deliveries (where 
Pérez Rivera \& Mes (2017) enforce delivery within a specified time window). The optimal decision will thus trade off the cost benefit of slower transportation modes with the risk of increased overdue penalties. In our planning model we anticipate uncertainty in travel times and the corresponding future decisions. One of the implications is that our modelling assumptions allow us to apply a different solution method to optimize the MDP than the one used in Pérez Rivera \& Mes (2017). As our MDP runs for a single shipment, it can be solved by means of backtracking. The tractability of this method provides us with an optimal policy and allows to gain insight in the trade-offs between the different transportation modes. The model we present in our paper is thus different, yet complementary to the work of Pérez Rivera \& Mes (2017).

The synchromodal planning model that we propose in this article, addresses disturbances and delays through stochastic travel times and corresponding probabilistic knowledge. Our synchromodal planning model is therefore both responsive, as optimal decisions are adjusted to the actual travel time duration, and anticipatory, as future costs resulting from the stochastic behavior are included in the optimal transportation mode choice. The proposed model is complementary to the existing synchromodal planning models.

\section{Synchromodal decision model}

We develop a model to determine the optimal transportation mode choice for a single shipment. We take the perspective of a shipper that wants to transport his freight order from origin to destination, thereby minimizing his total transportation and overtime delivery costs. Other shippers and logistics providers also make use of transportation services using the same transportation infrastructure on this corridor. This setting is inspired by the Physical Internet in which shippers can interact with others using digital platforms or digital control towers. Our planning model could be seen as a form of a-modal booking where the modal choice is not imposed in advance; we allow adjustments to the transportation mode choice based on real-time information about the travel time duration. Our model can then be executed by a shipper to decide which transportation mode to use at different segments of the route based on this real-time travel information.

In what follows we first introduce the transportation network in which the model operates in Section 3.1 , and describe the decision support model in Section 3.2 . The formulation of the model as a Markov decision process and its solution method are respectively discussed in Sections 3.3 and 3.4 . An extended version of the model including capacity restrictions on the transportation services is presented in Section 3.5 .

\subsection{Network description}

We model the multimodal transportation network as a directed graph $G(N, E)$, with $N$ the set of nodes, three mutually exclusive subsets, $N=N^{O} \cup N^{D} \cup N^{I}$, with $N^{O}$ and $N^{D}$ respectively the origin and destination node of the shipment and $N^{I}$ the set of intermediate nodes. Nodes correspond to locations in the physical network. Intermediate nodes represent truck, train and inland waterway terminals within an intermediate transshipment terminal. In these terminals the shipment can be transshipped between transportation modes, 


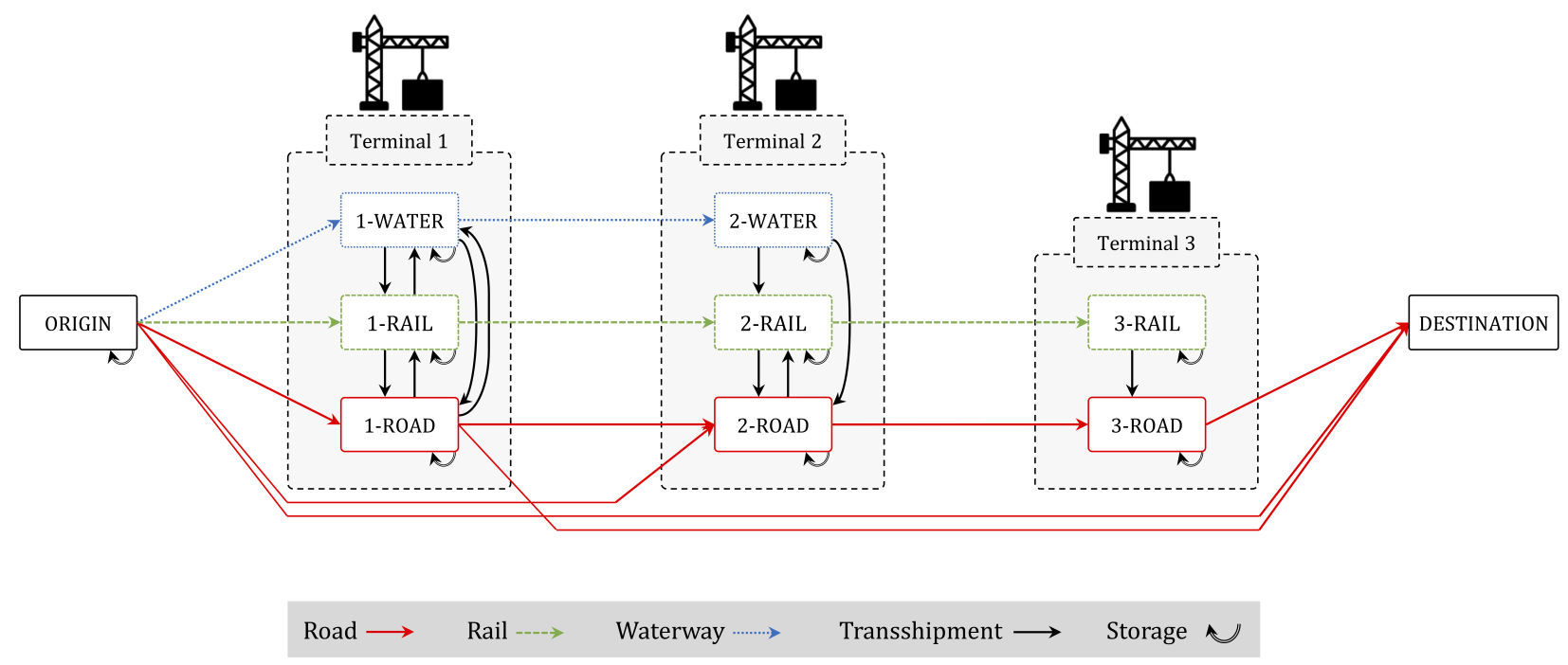

Figure 1: Graphical representation of a multimodal network featuring three transportation modes, connecting the origin and destination node through three intermediate transshipment terminals. The transshipment terminals include intermediate nodes for the transportation modes that arrive in or depart from the terminal.

forwarded using the same transportation mode, or kept in temporary storage to wait for transportation modes to arrive in the near future. Transshipment terminals only include nodes for the transportation modes that can arrive in or depart from the terminal. For instance, if there is no waterway arriving in or departing from the terminal, that transshipment terminal does not have a waterway terminal node.

The set $E$ covers the existing edges between nodes in the network. An edge $e$ in set $E$ is therefore defined by the two nodes $(i, j)$ it connects, with $i, j \in N$. Edges leaving and entering the same node are storage edges. They indicate that the shipment is temporarily stored in the node during one time period. Edges that connect intermediate nodes within a terminal denote transshipment edges between the modalities present in that terminal. Edges between transshipment terminals, or between a transshipment terminal and the origin/destination node, are transportation edges. The transportation mode is then determined by its adjacent nodes. Given this network description, a transportation route essentially consists of a sequence of edges connecting the origin node to the destination node. Figure 1 illustrates this graphical representation for a multimodal network with three intermediate transshipment terminals.

\subsection{Model description}

We develop a model to prescribe the optimal, cost-minimizing transportation mode choice to route a single shipment through the multimodal transportation network, represented by the directed graph $G(N, E)$. At each node, the optimal edge is determined. The decision can be to forward the freight over a transportation edge, to transship it to another transportation mode or to postpone transportation of the shipment for one period through a storage edge. The next decision moment is encountered upon arrival of the shipment in the end node of that specific edge. The resulting optimal decisions result in a sequence of edges, constructing 
175 a connected route from the origin node $N^{O}$ to the destination node $N^{D}$. The objective is to minimize total costs from origin to destination, including transportation costs, transshipment costs, storage costs and penalty costs incurred per time step that the shipment exceeds its delivery time.

The travel times of the transportation edges in the network are stochastic. That means that the transportation time is not fixed to one deterministic value, but it can have different scenarios, each with its own probability. If the travel time of an edge turns out to be one of the slower scenarios, then switching to a faster mode for the remaining part of the route can compensate for this tardiness in order to avoid the overdue delivery penalty costs. Vice versa, when the travel time appears to be in line with its faster scenarios, it can be exploited by switching to a slower, more sustainable, and less expensive transportation mode. Adapting transportation mode decisions to the actual travel time duration is an effective way to cope with stochastic travel times.

\subsection{Markov decision process model}

We formulate our model as a Markov decision process (MDP) with finite time horizon $T$. An MDP formulation is well-suited for dynamic decision-making problems over a multi-period horizon under stochastic circumstances. The state $s$ of the shipment is defined as $(i, t)$, capturing the node $i \in N$ in which the shipment is present at time $t \in[0, T]$. Each shipment has a size $f$ measured by a number of freight units. These can be conventional loading units such as containers, semi-trailers or swap bodies, or smaller units such as the modular boxes that will form a core element to materialize the Physical Internet. Upon arrival of the shipment at node $i$, a decision is made on the selection of the subsequent edge starting in node $i$, referred to as action $a$. Edges have a cost $c_{e}$ per freight unit and a service availability $b_{e}(t) \in\{0,1\}$, defining the service schedule whether transportation edge $e$ is available at time $t: b_{e}(t)=1$ indicates that the service is available at time $t$, and $b_{e}(t)=0$ if not. In Section 3.5 we extend our model to include capacity constraints on each transportation service. A service is then only eligible when it has sufficient capacity available to carry all the freight units in the shipment.

Let $\mathcal{A}(s)$ denote the set of admissible actions for state $s$, so that $a \in \mathcal{A}(s)$. The action space $\mathcal{A}(s)$ for $s=(i, t)$ is defined by all edges departing from node $i$ for which the edge is available at time step $t$ :

$$
\mathcal{A}(s)=\mathcal{A}(i, t)=\left\{(i, j) \in E \mid b_{(i, j)}(t)=1\right\} .
$$

The immediate cost of action $a$ equals the cost of the corresponding edge $e$, multiplied by the number of freight units $f$ in the shipment: $c(a)=c_{e} f$.

Action $a$ results in a transition from state $s$ to the next state $s^{\prime}$. The state transition is partially under control of the decision maker and partially subject to uncertainty. When edge $(i, j)$ is selected in state $s$, it is certain that the next state $s^{\prime}$ will be in node $j$. The time of arrival in node $j$, which is the second element of state $s^{\prime}$, is determined by the stochastic travel time $l_{e}$ of edge $(i, j)$. We model this stochastic behavior through a set of travel time scenarios $\Omega_{e}$ for each edge, where each scenario $\omega \in \Omega_{e}$ has a specified probability $p_{e}^{\omega}$. After the state transition, a new action is taken in state $s^{\prime}$. 
The objective is to find the optimal policy $\pi^{*}$, prescribing the set of actions $a$ in state $s$ that minimize the total costs from origin to destination. These costs are defined by the immediate cost $c(a)$ of action $a$ in state $s$ plus the expected future costs from state $s^{\prime}$ onward, in accordance with the probabilities from the stochastic state transition. This results in the following set of recursive equations for each state $s$ in the state space $\mathcal{S}$, where $v(s)$ denotes the value of state $s$, equal to the expected costs incurred from period $t$ onward:

$$
\begin{gathered}
v(s)=\min _{a \in A(s)}\left\{c(a)+\sum_{\omega \in \Omega} p_{a}^{\omega} v\left(s^{\prime}\right)\right\} \quad \forall s \in \mathcal{S}, \text { or } \\
v(i, t)=\min _{(i, j) \in A(i, t)}\left\{c_{(i, j)} f+\sum_{\omega \in \Omega} p_{(i, j)}^{\omega} v\left(j, t+l_{(i, j)}^{\omega}\right)\right\} \quad \forall(i, t) \in \mathcal{S} .
\end{gathered}
$$

Satisfying this set of recursive equations results in policy $\pi^{*}$, mapping the optimal action for every state $s=(i, t)$. The optimal actions are state-dependent, indicating that information about the shipment's state is used when following policy $\pi^{*}$. The ability to trace the shipment plays a major role here. Traceability provides real-time information at time $t$ related to the shipment's arrival in node $i$. As time $t$ is determined by the outcome of the stochastic travel time, policy $\pi^{*}$ adjusts the optimal decisions to the travel time outcome, implicitly captured by the time $t$ of the state.

We note that from the mathematical formulation of our model the key trade-offs between transportation, transshipment and penalty costs emerge. This allows us to capture sensitivities with respect to the input parameters of our model. For instance, assume the delivery time of an order is extended by one time period. This results in reduced expected future penalty costs, and allows slowing down the shipment at the benefit of lower transportation costs. Shifting to a slower mode, however, in turn increases the expected penalty costs. Slowing down a shipment in transit will thus be optimal when the increased penalty and transshipment costs are offset by the lower transportation costs. Note that the increased penalty costs due to switching to a slower mode can be mitigated by switching to a faster mode in case the real-time information reveals that the travel time duration is according to a slow scenario. We capture these dynamics numerically in Section 4 .

\subsection{Backtracking as the solution method}

To find the optimal policy $\pi^{*}$, we can solve equation set (2) by means of backtracking. A backtracking algorithm is initiated from a starting state, recursively goes in-depth for each action until reaching the final state, and then gradually tracks back to the preceding states to determine the optimal action and the value. Employing such a depth-first solution method is efficient as the recursive function only invokes the visited states, thereby only generating values for relevant states.

Setting the time of the shipment release at origin at $t=0$, the starting state of the backtracking is defined as $\left(N^{O}, 0\right)$. The final state $s_{\tau}=\left(N^{D}, t\right)$ is defined as the state in which the destination node is reached. Given that a penalty cost $\mu$ is incurred per time unit overdue, the terminal value $v_{\tau}$ is given by the following 
conditional equation, with $d$ the delivery time of the shipment:

$$
v_{\tau}\left(N^{D}, t\right)= \begin{cases}0 & \text { if } t \leq d, \\ (t-d) \mu & \text { if } t>d .\end{cases}
$$

The action space is adapted in accordance with the latest selection time of the edges, so that the shipment reaches its destination before the end of the time horizon ${ }^{1} T$. Denote $L S T_{e}$ the latest moment that edge $e$ can be selected so that the shipment can still arrive at the destination node within the time horizon under the assumption that the longest travel time materializes:

$$
L S T_{e}=L S T_{(i, j)}= \begin{cases}\max _{(j, k) \in E}\left\{L S T_{(j, k)}-\max _{\omega \in \Omega_{(i, j)}}\left\{l_{(i, j)}^{\omega}\right\}\right\} & \text { if } j \neq N^{D}, \\ T-\max _{\omega \in \Omega_{(i, j)}}\left\{l_{(i, j)}^{\omega}\right\} & \text { if } j=N^{D} .\end{cases}
$$

The action space $A(s)$ is then adjusted accordingly:

$$
A(s)=A(i, t)=\left\{(i, j) \in E \mid b_{(i, j)}(t)=1 \wedge L S T_{(i, j)} \leq t\right\} .
$$

\subsection{Extension to include capacity restrictions on intermodal transportation services}

In our model we have assumed that the transportation services have sufficient capacity available to carry drives the optimal transportation mode decision.

Denote $q_{e}(t) \in\{0,1\}$ the binary capacity feasibility variable, indicating whether the capacity availability on edge $e \in E$ at time $t$ is sufficient to cover the size $f$ of the shipment: $q_{e}(t)=1$, or not: $q_{e}(t)=0$. We augment the dimension of the state space by including the set of capacity feasibilities at time $t$ for all outgoing edges of node $i$, denoted by $\phi_{i}(t)=\left\{q_{(i, j)}(t), \forall j \in N:(i, j) \in E\right\}$. The state $s=\left(i, t, \phi_{i}(t)\right)$ then respectively captures the shipment's node, time and capacity feasibility of all edges departing from the current node. The action space $\mathcal{A}(s)$ is refined to only include edges with sufficient capacity available to facilitate shipment:

$$
\mathcal{A}(s)=\mathcal{A}\left(i, t, \phi_{i}(t)\right)=\left\{(i, j) \in E \mid q_{(i, j)}(t)=1\right\}
$$

\footnotetext{
${ }^{1}$ To enclose all non-redundant solutions, we set the time horizon $T$ equal to the path with the longest possible travel time duration from origin to destination, taking travel time scenarios and service schedules into account.
} 


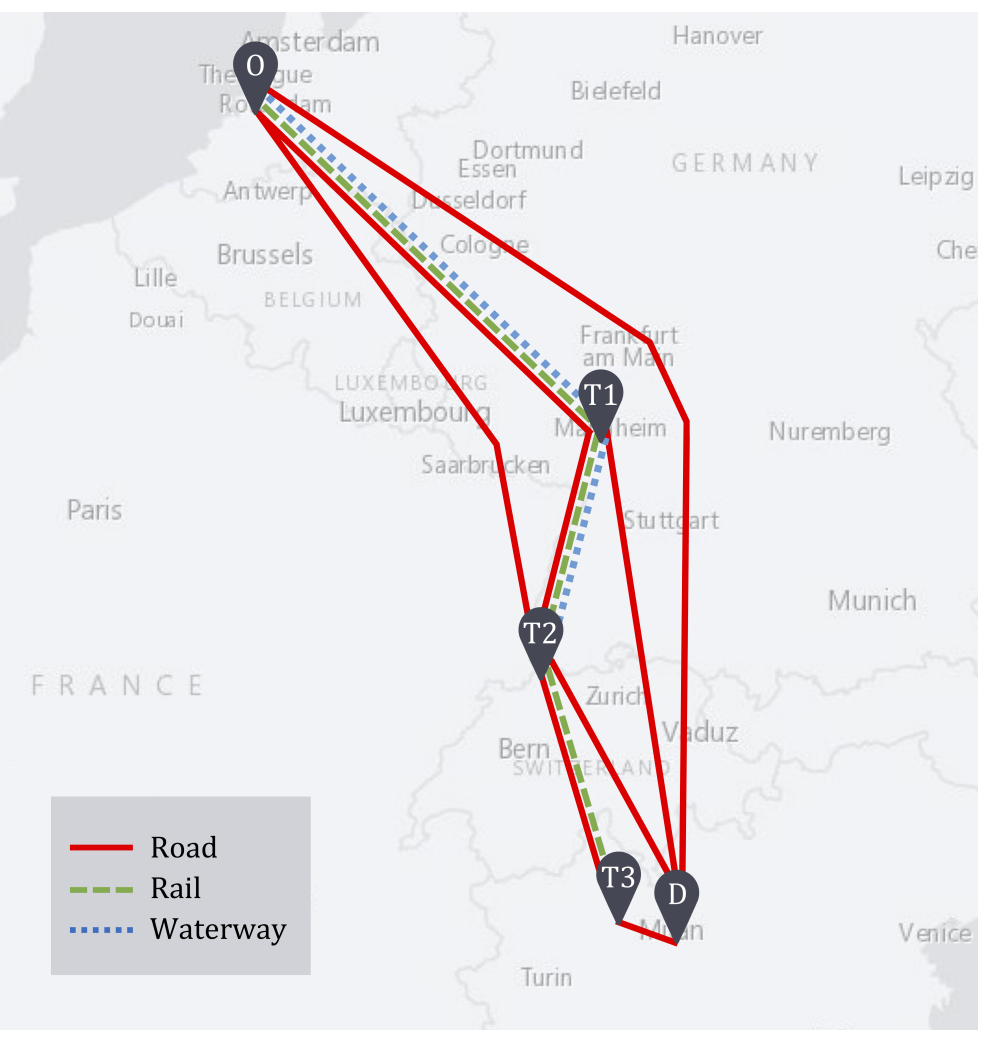

Figure 2: Map of the network from Rotterdam (O) to the destination location near Milan (D), with intermediate terminals in Mannheim (T1), Basel (T2) and Busto Arsizio (T3).

When taking action $a \in \mathcal{A}(s)$, the transition to the next state $s^{\prime}$ is now subject to two stochastic elements: the travel time of the chosen edge $(i, j)$ and the capacity availability upon arrival at node $j$. The latter is modeled as follows. Let $Q_{e}(t)$ be the set of possible capacity scenarios for edge $e$ at time $t$, and define $\Phi_{j}\left(t^{\prime}\right)$ the Cartesian product over all possible capacity scenarios $Q_{e}\left(t^{\prime}\right)$ for all outgoing edges of node $j$ :

$$
\Phi_{j}\left(t^{\prime}\right)=Q_{(j, 1)}\left(t^{\prime}\right) \times Q_{(j, 2)}\left(t^{\prime}\right) \times \ldots=\left\{\left\{q_{(j, 1)}, q_{(j, 2)}, \ldots\right\} \mid q_{(j, k)} \in Q_{(j, k)}\left(t^{\prime}\right) \text { for all } k \in N:(j, k) \in E\right\} .
$$

Upon transitioning to state $s^{\prime}=\left(j, t^{\prime}, \phi_{j}\left(t^{\prime}\right)\right)$ we observe the available capacities of all outgoing edges from node $j$ at time $t^{\prime}$, given by $\phi_{j}\left(t^{\prime}\right) \in \Phi_{j}\left(t^{\prime}\right)$. Let $p_{j}^{\phi}$ denote the probability of a particular capacity availability set $\phi_{j}\left(t^{\prime}\right) \in \Phi_{j}\left(t^{\prime}\right)$. To obtain the optimal policy $\pi^{*}$, we solve the set of recursive equations (8) by means of backtracking:

$$
\begin{gathered}
v(s)=\min _{a \in A(s)}\left\{c(a)+\sum_{\omega \in \Omega} p_{a}^{\omega} \sum_{\phi_{j} \in \Phi_{j}\left(t^{\prime}\right)} p_{j}^{\phi} v\left(s^{\prime}\right)\right\} \quad \forall s \in \mathcal{S}, \text { or } \\
v\left(i, t, \phi_{i}(t)\right)=\min _{(i, j) \in A\left(i, t, \phi_{i}(t)\right)}\left\{c_{(i, j)} f+\sum_{\omega \in \Omega} p_{(i, j)}^{\omega} \sum_{\phi_{j} \in \Phi_{j}\left(t+l_{(i, j)}^{\omega}\right)} p_{j}^{\phi} v\left(j, t+l_{(i, j)}^{\omega}, \phi_{j}\left(t+l_{(i, j)}^{\omega}\right)\right)\right\} \quad \forall\left(i, t, \phi_{i}(t)\right) \in \mathcal{S} .
\end{gathered}
$$




\begin{tabular}{cccc}
\hline Corridor & Road & Rail & Waterways \\
\hline \hline Rotterdam $\rightarrow$ Mannheim & $560 \mathrm{~km}$ & $570 \mathrm{~km}$ & $600 \mathrm{~km}$ \\
\hline Rotterdam $\rightarrow$ Basel & $770 \mathrm{~km}$ & & \\
\hline Rotterdam $\rightarrow$ Milan & $1190 \mathrm{~km}$ & & \\
\hline Mannheim $\rightarrow$ Basel & $280 \mathrm{~km}$ & $270 \mathrm{~km}$ & $260 \mathrm{~km}$ \\
\hline Mannheim $\rightarrow$ Milan & $630 \mathrm{~km}$ & & \\
\hline Basel $\rightarrow$ Busto Arsizio & & $360 \mathrm{~km}$ & \\
\hline Basel $\rightarrow$ Milan & $420 \mathrm{~km}$ & & \\
\hline Busto Arsizio $\rightarrow$ Milan & $50 \mathrm{~km}$ & & \\
\hline
\end{tabular}

Table 1: Distances between origin (Rotterdam), the transshipment terminals (Mannheim, Basel and Busto Arsizio) and the destination (Milan), obtained through Google Maps, TENtec Interactive Maps (European Commission, 2020), and The Blue Road Map (Bureau Voorlichting Binnenvaart, 2020).

\section{Numerical experiment}

We numerically demonstrate the application of our synchromodal planning model for a single shipment that requires transportation from origin to destination. Note that our model is versatile to any network and parameter configuration. As such it can be used to evaluate synchromodal planning for a given network setting. For illustration purposes, we report and discuss the results of the application to one specific case study of a tri-modal corridor from Rotterdam (origin O) to a destination (D) near Milan, with intermediate transshipment terminals in Mannheim (T1), Basel (T2) and Busto Arsizio (T3), as presented in Figure 2

From Busto Arsizio we can only reach the final destination by road, indicating the last-mile delivery. Note that this network also corresponds to the graphical representation in Figure 1. In Table 1 we report the distances of each stretch of this route. These distances are obtained through Google Maps, TENtec Interactive Maps (European Commission, 2020), and The Blue Road Map (Bureau Voorlichting Binnenvaart, 2020).

We consider the time step in our experiment equal to one hour, and thus express travel times in hours. The stochastic travel times and their corresponding probabilities are as follows.

- Travel times for road transportation are modeled by means of a shifted binomial distribution, $B(n, 0.15)+n$, with $n$ the minimum travel time for each stretch, determined by a maximum average speed of $70 \mathrm{~km} / \mathrm{h}$ (reported by Demir et al. (2017) in absence of congestion). The resulting average speed of this distribution is approximately $60 \mathrm{~km} / \mathrm{h}$ and is consistent with Ambra et al. (2019a). We used the binomial distribution in line with Chiang \& Roberts (1980), who proposed right-skewed distributed travel times for road transportation.

- The travel time scenarios for rail transportation assume an average speed of $30 \mathrm{~km} / \mathrm{h}$ for rail transportation (according to a European Commission (2014) report, the European Court of Auditors (2016) and Li et al. (2015)) and take the delays into account, reported in Barta et al. (2012). 


\begin{tabular}{ccc}
\hline Edge type & Cost $(€ /$ TEU $)$ & Emission $\left(\mathrm{kg} \mathrm{CO}_{2}\right.$-eq/TEU $)$ \\
\hline \hline Road & $1.00 / \mathrm{km}$ & $0.84 / \mathrm{km}$ \\
Rail & $0.65 / \mathrm{km}$ & $0.21 / \mathrm{km}$ \\
Waterway & $0.25 / \mathrm{km}$ & $0.356 / \mathrm{km}$ \\
Transshipment & 25 & 2.74 \\
Storage & 0.01 & - \\
\hline
\end{tabular}

Table 2: Assumed cost and emission parameters for the different edge types in our numerical experiment.

\footnotetext{
${ }^{2}$ Note that this does not necessarily need to be the case; our modelling approach also allows stochastic transshipment times.

${ }^{3}$ Although we will refer to freight units as TEUs, a freight unit can equal any other intermodal loading unit.
} 

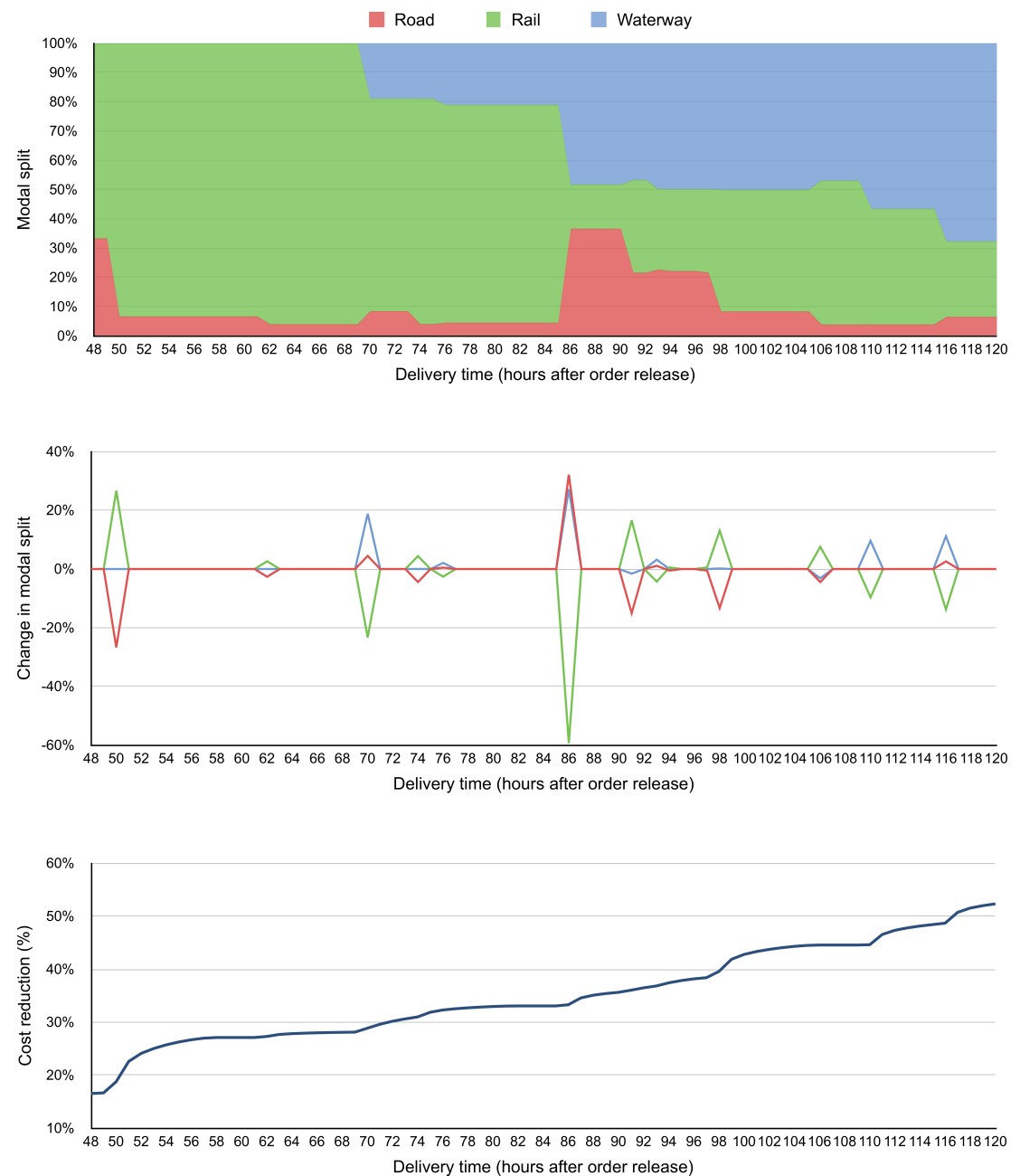

Figure 3: We increase the delivery time from 48 hours to 120 hours after order release and show the impact on the modal split (top panel), the change in modal split compared to a delivery time of one hour earlier (middle panel) and the expected cost reduction compared to unimodal road transportation (bottom panel).

transportation (the cheapest transportation mode) tends to increase as the urgency of the delivery goes down, represented by a longer delivery time. The shares of road and rail transportation, however, are non-monotonic such that is not straightforward to conclude whether or not the shift towards waterways is generally made from road and/or rail transportation. We attribute this behaviour to the complex structure of our network but provide insight on the dynamics of our specific setup in the next paragraph.

The middle graph of Figure 3 depicts the interaction between different transportation modes when the delivery time is extended with one time period. It appears that for longer delivery times, road transportation is substituted for rail transportation whenever the share of waterway transportation remains stable. A similar effect is observed between rail and waterway transportation when the share of road does not change. This demonstrates how shifting to slower transportation modes becomes possible as the urgency of the delivery reduces. On the other hand, we observe that an increased usage of waterways is often accompanied by an 
increased share of road transportation. This is explained by the fact that road transportation can compensate the longer travel time durations that may occur with slow inland waterways.

Comparing the cost performance of synchromodality to unimodal road transportation (bottom graph of Figure 3), we observe how shippers can benefit from stronger cost reductions when they can reduce the urgency of their shipments. Modest improvements in cost reductions coincide with a stable modal split, as observed in the middle graph of Figure 3 whereas larger improvements in cost reductions correspond with a modal shift to less expensive transportation modalities.

\subsection{Synchromodal versus Intermodal transportation planning}

We benchmark the performance of synchromodal planning against an intermodal planning policy. Intermodal transportation is defined as the combination of different modes along the transportation route, but without the possibility to adjust the modal choice based on for instance the actual travel times Reis, 2015. Dong et al., 2018). Using the terminology of our Markov decision process, this means that decisions are based only on the node-element of the state, but not on the time dimension of the state. The transportation modes for the different route segments are thus determined at the start of the shipment, and not adjusted based on real-time information about travel times. As synchromodal transportation planning generalizes intermodal planning, it will always outperform intermodality in terms of costs. Yet, benchmarking with an intermodal policy provides insight in the value of real-time adjustments of the modal choice.

Table 3 compares the key performance measures of synchromodal and intermodal transportation by aggregating the results of Figure 3. More specifically, we applied our model for a single shipment under different delivery times, ranging from 48 hours (2 days) to 120 hours (5 days) after order release, and report their average cost performance, modal split and emission reduction compared to unimodal road transportation. To make a fair cost comparison between dynamic synchromodal planning and static intermodal planning, we consider in both cases only the variable cost of the transportation service and assume the fixed cost of intermodal transport to be incurred by the network operator offering these services through the digital platform. The average modal split is defined as the ratio of the number of kilometers shipped on road/rail/waterway over the total number of kilometers travelled from origin to destination.

We observe that, relative to unimodal road transportation planning, synchromodal planning yields $1.35 \%$ higher cost savings than intermodal planning when we average over all considered delivery times in our experiment; the 5th and 95th percentile of this increase in cost savings are respectively $0 \%$ and $3.95 \%$. Also, we find that synchromodality improves the timeliness of deliveries. While the $\%$ of on-time delivery is comparable for both policies, the expected number of periods overdue is reduced when real-time decisions are allowed. Notably, emissions are slightly higher in the synchromodal case: compared to intermodal transportation, it relies more on road and waterway transportation, which both have higher $\mathrm{CO}_{2}$ factors than rail transportation (Table 2). This is related to our objective function of cost minimization: inland waterway transportation is less expensive than rail. As a result of this, synchromodality will exploit its flexibility to use the low-cost waterway transportation more often than intermodality does. At the same 


\begin{tabular}{ccccccc}
\hline $\begin{array}{c}\text { Transportation } \\
\text { planning policy }\end{array}$ & $\begin{array}{c}\text { \%Cost improvement } \\
\text { vs. unimodal road }\end{array}$ & $\begin{array}{c}\text { \%On-time } \\
\text { delivery }\end{array}$ & $\begin{array}{c}\text { Average periods } \\
\text { late when overdue }\end{array}$ & $\begin{array}{c}\text { \%Road } \\
\text { vRail }\end{array}$ & $\begin{array}{c}\text { \% Waterway } \\
\text { vs. unimodal road }\end{array}$ \\
\hline \hline Synchromodal & $35.18 \%$ & $89.82 \%$ & 1.96 & $10.16 \%$ & $60.10 \%$ & $29.74 \%$ \\
Intermodal & $33.83 \%$ & $90.30 \%$ & 2.75 & $5.48 \%$ & $70.44 \%$ & $24.08 \%$ \\
\hline
\end{tabular}

Table 3: Results from the experiment for the synchromodal and intermodal transportation policy. Cost improvement and emission reduction are compared to unimodal road transportation. The mode percentages indicate the modal split, defined as the ratio of number of kilometers shipped on the mode over the total number of kilometers.

time, synchromodality relies more often on fast road transportation to mitigate possible delays in the slower transportation modes. For these reasons, synchromodality may have higher emissions than intermodality. We restrict our objective function to costs, mainly driven by current industry practice. An alternative approach could be to add a second objective function to minimize emissions and find the Pareto curve that considers costs and emissions. In the next section we evaluate how the performance measures change under different parameter settings.

\subsection{Sensitivity analysis}

\subsubsection{Impact of the overtime delivery penalty cost}

The penalty for an overtime delivery impacts the modal choice: a higher penalty cost creates a substitution from slower to faster transportation modes, which are also more expensive. This increases total costs, or equivalently, reduces the cost benefit compared to unimodal road transportation. From the left panel of Figure 4 we observe the average cost reduction relative to unimodal road transportation as the penalty cost increases, for which the slope is smaller under synchromodal planning than under intermodal. As a result, the cost benefit of synchromodality over intermodality increases with higher penalty costs: as the penalty cost goes up from $€ 10 /$ hour to $€ 90 /$ hour, the benefit of synchromodality compared to intermodality grows from $0.33 \%$ to $1.71 \%$. We note that these cost improvements are averaged over the different delivery times (Figure 3. bottom panel illustrates for a penalty cost of $€ 50 /$ hour how these cost improvements range depending on the delivery time). The 5th and 95th percentile of the cost improvement of synchromodal versus intermodal planning over these delivery times range from $[0 \%, 1.35 \%]$ for the lowest considered penalty cost of $€ 10 /$ hour up to $[0 \%, 5.06 \%]$ for the highest considered penalty cost of $€ 90 /$ hour. The right panel of Figure 4 indicates that the relative cost improvement of synchromodal planning is partly due to the lower

35 level of tardiness when a delivery is overdue compared to intermodal planning. Synchromodality thus not only performs better in terms of costs, it also reduces the expected lateness in case of overdue delivery.

\subsubsection{Impact of the service frequency of intermodal transport services}

We also evaluate the impact of service frequency for rail and waterway transportation, as their availability drives the opportunity to switch modes along the route. We consider service schedules ranging from one service every other day to three services per day, respectively for rail transportation, for waterway transportation and for both. Figure 5 illustrates how a lower service frequency results in lower cost reductions compared to 

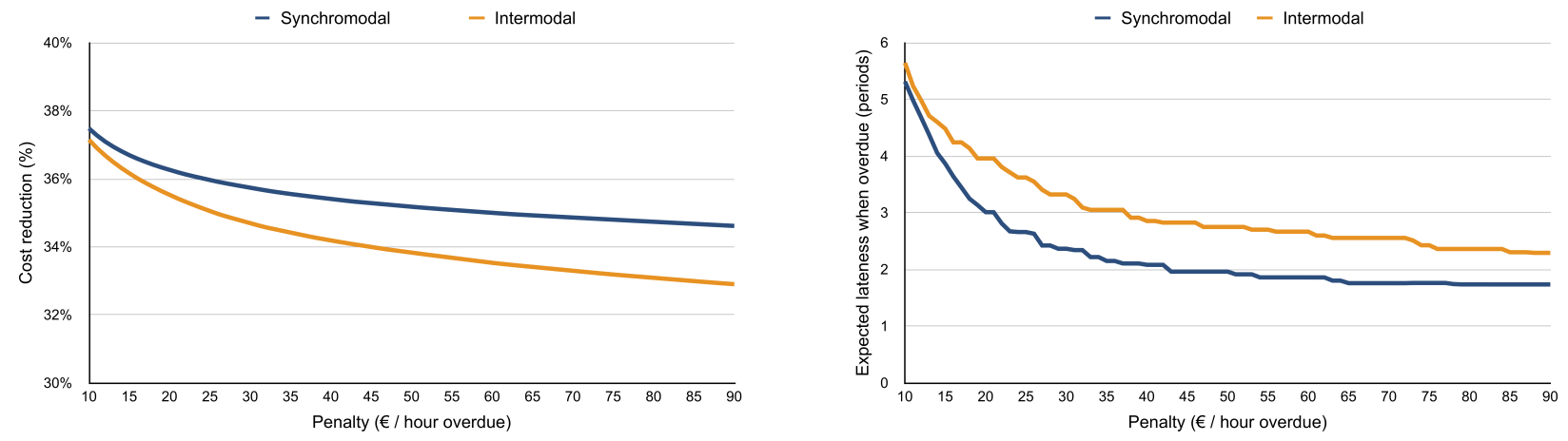

Figure 4: Sensitivity analysis on the late delivery penalty costs for synchromodal and intermodal transportation. Left: cost reduction compared to unimodal road. Right: expected number of periods late in case the delivery is overdue.
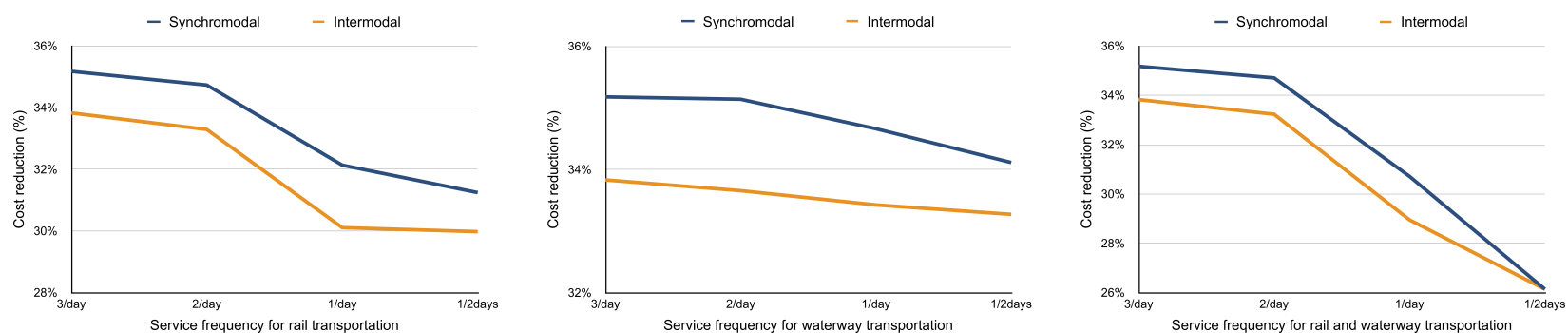

Figure 5: Sensitivity analysis on the service frequency for rail (left), waterway (middle) and both rail and waterway (right). The graphs show the cost reductions of synchromodal and intermodal transportation compared to unimodal road transportation.

unimodal road, both for intermodal and synchromodal transportation. When the frequency of rail services goes down (left graph of Figure 5), rail transportation is primarily replaced by road, resulting in overall higher costs and thus smaller cost reductions compared to unimodal road transportation. The cost difference of synchromodal relative to intermodal planning remains fairly stable for the service frequencies considered in this experiment. We do find that the relative benefit of synchromodality compared to intermodality goes slightly down when there are fewer waterway frequencies available (middle graph of Figure 5), as there are less opportunities to switch to the slowest, less expensive, transportation mode. When the service frequency is reduced for both modes (right graph of Figure 5), cost improvement compared to unimodal road decreases more severely, and eventually the difference between synchromodal and intermodal transportation becomes negligible. When alternative transportation modes are not frequently available, there is little benefit in revising the modal choice based on real-time information, as they may not have a service readily available. We can conclude that the benefits of synchromodality increase with a higher service frequency of transportation modes.

\subsubsection{Impact of service punctuality}

We investigate the impact of the 'punctuality' of the transportation services, by modelling different travel time distributions. We consider a base case, a high-punctuality and a low-punctuality case, which consider the same travel time scenarios as in Appendix A, albeit with different probabilities. Travel time probabilities 


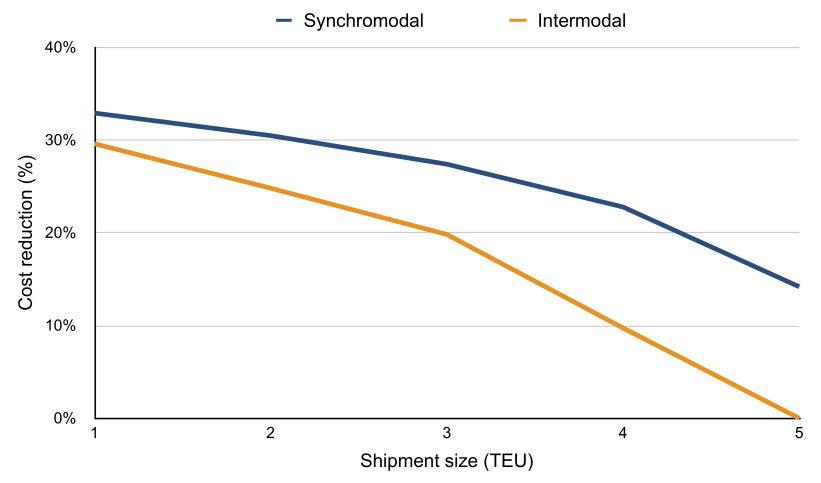

Figure 6: Sensitivity analysis on the shipment size when the capacity availability on transportation services is stochastic and follows a discrete uniform distribution $\sim U\{0,5\}$. The graph shows cost reductions compared to unimodal road.

are assumed to be uniformly distributed in the base case, and distributed according to a symmetrical beta-

binomial distribution with $50 \%$ lower (higher) variance compared to the base case in the high-punctuality (low-punctuality) case. These distributions all have the same average travel time, but a different variance, indicating a different degree in punctuality (see Appendix B.1 for a visual of these distributions). Our analysis (see Appendix B.2 indicates that the results are robust with respect to the degree of punctuality, with at most a one percent difference in cost reduction compared to unimodal road transportation.

\subsubsection{Impact of capacity restrictions}

To investigate the effect of limited capacity availability on the transportation services, we use the MDP model described in Section 3.5 and assume a random number of freight units to be available on all transportation services. This stochasticity comes from the fact that other shippers also make use of the same transportation services. Its probability distribution is driven by the aggregation of a potentially large number of shippers on the platform, and henceforth they are not directly impacted by one individual shipment. We assume transshipment and storage edges to be unrestricted in capacity, although the model could cope with capacity restrictions on these edges as well. In our numerical experiment we let the available capacity be random between 0 and 5 TEUs for road, rail and waterway services, with probabilities according to a discrete uniform distribution $\sim U\{0,5\}$, and let the size of the shipment range from 1 to 5 TEUs.

Figure 6 shows how the cost reductions compared to unimodal road transportation go down rapidly as the shipment size increases with respect to the available capacity of intermodal transportation services. A large shipment will in those cases less likely fit into the available capacity, which makes them rely more on road transportation. Road transportation is faster and more flexible as it is not constrained by a service schedule. The sharper reduction of the cost improvement under intermodality compared to synchromodality also

illustrates the lower flexibility of intermodality. Due to its lower responsiveness to the capacity availability, it will rely even more on expensive road transportation. 


\subsection{Discussion}

Our synchromodal transportation planning model exploits real-time information to determine the optimal modal choice that minimizes the total transportation and overtime delivery costs for a single shipment. This

transit. Third, our algorithm could also be implemented in synchromodal platforms that combine these realtime tracking tools with decision support models, such as the SYNCHRO-NET platform (Giusti et al. 2019a) 
and the ICONET platform (ICONET Project, 2020). Finally, we note that our model is computationally efficient, only taking a fraction of a second per order, which renders it amenable for implementation in digital platforms or digital control towers.

\section{Conclusion}

We present a model to support synchromodal transportation planning for a single shipment to determine its optimal modal choice in a multimodal network. The model allows adjustments to the modal choice based on real-time travel information, such as travel time duration and capacity availability. We formulate our model as a finite-horizon Markov decision process, and solve it through backtracking. The synchromodal planning policy is both responsive, as optimal decisions are adjusted to the actual travel time information, and anticipatory, as future decisions resulting from the stochastic behavior are included when determining the optimal modal choice.

In a numerical experiment we evaluate the value of making adjustments to the modal choice based on realto faster or slower transportation modes. The benefit of these threshold policies is that they are easier to implement and interpret compared to our numerical backtracking approach, yet at the expense of optimality 
for more complex settings such as the one we studied. Future research could also consider including inventory levels of the shippers into the dynamics of our problem.

Dong, C., Boute, R., McKinnon, A., \& Verelst, M. (2018). Investigating synchromodality from a supply chain perspective. Transportation Research Part D: Transport and Environment, 61, 42-57.

European Commission (2011). Transport 2050: Commission outlines ambitious plan to increase mobility and

ALICE (2014). Corridors, Hubs and Synchromodality: Research Innovation Roadmap. URL: http:// euetpl-kirechlik.savviihq.com/wp-content/uploads/2015/08/W26mayo-kopie.pdf

Ambra, T., Caris, A., \& Macharis, C. (2019a). Should I stay or should I go? Assessing intermodal and synchromodal resilience from a decentralized perspective. Sustainability, 11, 1765.

Ambra, T., Caris, A., \& Macharis, C. (2019b). Towards freight transport system unification: reviewing and combining the advancements in the physical internet and synchromodal transport research. International Journal of Production Research, 57, 1606-1623.

Barta, J., Rizzoli, A. E., Salani, M., \& Gambardella, L. M. (2012). Statistical modelling of delays in a rail freight transportation network. In Proceedings of the 2012 Winter Simulation Conference (WSC) (pp.

Behdani, B., Fan, Y., Wiegmans, B., \& Zuidwijk, R. (2014). Multimodal schedule design for synchromodal freight transport systems. Behdani, B., Fan, Y., Wiegmans, B., E Zuidwijk, (pp. 424-444).

Bureau Voorlichting Binnenvaart (2020). The Blue Road Map. Retrieved June 23, 2020 from https: //www.blueroadmap.nl/

Chiang, Y.-S., \& Roberts, P. O. (1980). A note on transit time and reliability for regular-route trucking. Transportation Research Part B: Methodological, 14, 59-65.

Crainic, T. G., \& Laporte, G. (1997). Planning models for freight transportation. Design and operation of civil and environmental engineering systems. Wiley-Interscience, New York, (pp. 343-394).

Demir, E., Hrušovskỳ, M., Jammernegg, W., \& Van Woensel, T. (2017). Methodological approaches to reliable and green intermodal transportation. In Sustainable Logistics and Transportation (pp. 153179). Springer. reduce emissions. URL: https://europa.eu/rapid/press-release_IP-11-372_en.htm.

European Commission (2014). Rhine-Alpine Core Network Corridor Study: Final Report. URL: https: //ec.europa.eu/transport/sites/transport/files/rhine-alpine_study_0.pdf. 
European Commission (2020). Mobility and Transport: TENtec Interactive Maps. Retrieved June 23, 2020 from https://ec.europa.eu/transport/infrastructure/tentec/tentec-portal/map/maps.html.

505

European Court of Auditors (2016). Rail freight transport in the EU: still not on the right track. URL: https://www.eca.europa.eu/Lists/ECADocuments/SR1608/SRRAILFREIGHTEN.pdf

Giusti, R., Iorfida, C., Li, Y., Manerba, D., Musso, S., Perboli, G., Tadei, R., \& Yuan, S. (2019a). Sustainable and de-stressed international supply-chains through the SYNCHRO-NET approach. Sustainability, 11, 1083.

Giusti, R., Manerba, D., Bruno, G., \& Tadei, R. (2019b). Synchromodal logistics: An overview of critical success factors, enabling technologies, and open research issues. Transportation Research Part E: Logistics and Transportation Review, 129, 92-110.

ICONET Project (2020). Retrieved July 3, 2020 from https://www.iconetproject.eu/

International Transport Forum (2017). ITF Transport Outlook 2017. URL: https://www.oecd-ilibrary. org/content/publication/9789282108000-en.

Lemmens, N., Gijsbrechts, J., \& Boute, R. (2019). Synchromodality in the Physical Internet-dual sourcing and real-time switching between transport modes. European Transport Research Review, 11, 19.

Li, L., Negenborn, R. R., \& De Schutter, B. (2015). Intermodal freight transport planning-A receding horizon control approach. Transportation Research Part C: Emerging Technologies, 60, 77-95.

MarineTraffic (2020). Retrieved June 23, 2020 from https://www.marinetraffic.com/nl/ais/home.

Meers, D., Macharis, C., Vermeiren, T., \& van Lier, T. (2017). Modal choice preferences in short-distance hinterland container transport. Research in Transportation Business 83 Management, 23, 46-53.

Mes, M. R., \& Iacob, M.-E. (2016). Synchromodal transport planning at a logistics service provider. In Logistics and Supply Chain Innovation: Bridging the Gap between Theory and Practice (pp. 23-36). Springer.

Montreuil, B. (2011). Toward a physical internet: meeting the global logistics sustainability grand challenge. Logistics Research, 3, 71-87.

Montreuil, B., Meller, R. D., \& Ballot, E. (2012). Physical internet foundations. IFAC Proceedings Volumes, $45,26-30$.

Otten, M. B. J., Hoen, M., \& Boer, L. (2016). Stream freight transport 2016: Emissions of freight transport modes. URL: https://www.cedelft.eu/publicatie/stream_freight_transport_2016/1855.

Pérez Rivera, A. E., \& Mes, M. R. (2016). Anticipatory freight selection in intermodal long-haul round-trips. Transportation Research Part E: Logistics and Transportation Review, 105, 176-194. 
Pérez Rivera, A. E., \& Mes, M. R. (2017). Anticipatory Scheduling of Freight in a Synchromodal Transportation Network. Transp. Res. Part E: Logist. Transp. Rev., 105, 176-194.

Pérez Rivera, A. E., \& Mes, M. R. (2019). Integrated scheduling of drayage and long-haul operations in synchromodal transport. Flexible services and manufacturing journal, 31, 763-806.

Reis, V. (2015). Should we keep on renaming a+ 35-year-old baby? Journal of Transport Geography, 46, $173-179$.

van Riessen, B., Negenborn, R. R., \& Dekker, R. (2015a). Synchromodal container transportation: an overview of current topics and research opportunities. In international conference on computational logistics (pp. 386-397). Springer.

van Riessen, B., Negenborn, R. R., Dekker, R., \& Lodewijks, G. (2015b). Service network design for an intermodal container network with flexible transit times and the possibility of using subcontracted transport. International Journal of Shipping and Transport Logistics, 7, 457-478.

van Riessen, B., Negenborn, R. R., Lodewijks, G., \& Dekker, R. (2015c). Impact and relevance of transit disturbances on planning in intermodal container networks using disturbance cost analysis. Maritime Economics $\&$ Logistics, 17, 440-463.

Singh, P., van Sinderen, M., \& Wieringa, R. (2016). Synchromodal transport: pre-requisites, activities and effects. In Ils conference (pp. 1-4).

SteadieSeifi, M., Dellaert, N. P., Nuijten, W., Van Woensel, T., \& Raoufi, R. (2014). Multimodal freight transportation planning: A literature review. European journal of operational research, 233, 1-15.

Tavasszy, L., Van der Lugt, L., Janssen, G., \& Hagdorn, E. (2010). Verkenning Synchromodaal Transportsysteem. TNO-rapport, .

${ }_{555}$ Tavasszy, L. A., Behdani, B., \& Konings, R. (2015). Intermodality and Synchromodality. Available at SSRN 2592888, .

Wiegmans, B., \& Konings, R. (2015). Intermodal inland waterway transport: Modelling conditions influencing its cost competitiveness. The Asian Journal of Shipping and Logistics, 31, 273-294. 


\section{Appendix A. Stochastic travel times: scenarios and probabilities}

\section{Appendix A.1. Road transportation}

The different stochastic travel time scenarios and their probabilities are derived as follows. The minimum travel times of road transportation are driven by a maximum average speed of $70 \mathrm{~km} / \mathrm{h}$, which was reported by Demir et al. (2017) in absence of congestion. We used Chiang \& Roberts (1980) to validate the rightskewed binomial distribution. The binomial distribution applied in our numerical study implies an average speed of approximately $60 \mathrm{~km} / \mathrm{h}$ for road transportation, which is consistent with the average speed reported by Ambra et al. (2019a).

\begin{tabular}{|c|c|c|c|c|c|c|c|c|}
\hline \multirow{3}{*}{$\begin{array}{c}\text { Corridor } \\
\text { Rotterdam } \rightarrow \text { Mannheim } \\
(560 \mathrm{~km})\end{array}$} & \multicolumn{8}{|c|}{ Travel time scenario and probability } \\
\hline & $8 \mathrm{~h}$ & $9 \mathrm{~h}$ & $10 \mathrm{~h}$ & $11 \mathrm{~h}$ & $12 \mathrm{~h}$ & & & \\
\hline & $27.25 \%$ & $38.47 \%$ & $23.76 \%$ & $8.39 \%$ & $2.13 \%$ & & & \\
\hline Rotterdam $\rightarrow$ Basel & $11 \mathrm{~h}$ & $12 \mathrm{~h}$ & $13 \mathrm{~h}$ & $14 \mathrm{~h}$ & $15 \mathrm{~h}$ & $16 \mathrm{~h}$ & & \\
\hline$(770 \mathrm{~km})$ & $16.73 \%$ & $32.48 \%$ & $28.66 \%$ & $15.17 \%$ & $5.36 \%$ & $1.60 \%$ & & \\
\hline Rotterdam $\rightarrow$ Milan & $17 \mathrm{~h}$ & $18 \mathrm{~h}$ & $19 \mathrm{~h}$ & $20 \mathrm{~h}$ & $21 \mathrm{~h}$ & $22 \mathrm{~h}$ & $23 \mathrm{~h}$ & $24 \mathrm{~h}$ \\
\hline$(1190 \mathrm{~km})$ & $6.31 \%$ & $18.93 \%$ & $26.73 \%$ & $23.59 \%$ & $14.57 \%$ & $6.68 \%$ & $2.36 \%$ & $0.83 \%$ \\
\hline Mannheim $\rightarrow$ Basel & $4 \mathrm{~h}$ & $5 \mathrm{~h}$ & $6 \mathrm{~h}$ & $7 \mathrm{~h}$ & & & & \\
\hline$(280 \mathrm{~km})$ & $52.20 \%$ & $36.85 \%$ & $9.75 \%$ & $1.20 \%$ & & & & \\
\hline Mannheim $\rightarrow$ Milan & $9 \mathrm{~h}$ & $10 \mathrm{~h}$ & $11 \mathrm{~h}$ & $12 \mathrm{~h}$ & $13 \mathrm{~h}$ & $14 \mathrm{~h}$ & & \\
\hline$(630 \mathrm{~km})$ & $23.16 \%$ & $36.79 \%$ & $25.97 \%$ & $10.69 \%$ & $2.83 \%$ & $0.56 \%$ & & \\
\hline Basel $\rightarrow$ Milan & $6 \mathrm{~h}$ & $7 \mathrm{~h}$ & $8 \mathrm{~h}$ & $9 \mathrm{~h}$ & $10 \mathrm{~h}$ & & & \\
\hline$(420 \mathrm{~km})$ & $37.72 \%$ & $39.93 \%$ & $17.62 \%$ & $04.15 \%$ & $0.58 \%$ & & & \\
\hline Busto Arsizio $\rightarrow$ Milan & $1 \mathrm{~h}$ & & & & & & & \\
\hline$(50 \mathrm{~km})$ & $100 \%$ & & & & & & & \\
\hline
\end{tabular}


Appendix A.2. Rail transportation

The travel time scenarios for rail transportation are derived as follows. The average speed of $30 \mathrm{~km} / \mathrm{h}$ for rail transportation comes from a European Commission report (European Commission, 2014), the European Court of Auditors (2016) and Li et al. (2015) and the distances for the rail routes are constructed based on TENtec Interactive Maps (European Commission, 2020) and Google Maps. The delays in rail transportation are based on Barta et al. (2012).

\begin{tabular}{ccccccccc}
\hline Corridor & \multicolumn{7}{c}{ Travel time scenario and probability } \\
\hline \hline Rotterdam $\rightarrow$ Mannheim & $19 \mathrm{~h}$ & $20 \mathrm{~h}$ & $21 \mathrm{~h}$ & $22 \mathrm{~h}$ & $23 \mathrm{~h}$ & $24 \mathrm{~h}$ & $25 \mathrm{~h}$ & $26 \mathrm{~h}$ \\
$(570 \mathrm{~km})$ & $82.00 \%$ & $4.00 \%$ & $2.00 \%$ & $2.00 \%$ & $0.50 \%$ & $0.50 \%$ & $3.00 \%$ & $6.00 \%$ \\
\hline Mannheim $\rightarrow$ Basel & $9 \mathrm{~h}$ & $10 \mathrm{~h}$ & $11 \mathrm{~h}$ & $12 \mathrm{~h}$ & & & & \\
$(270 \mathrm{~km})$ & $81.00 \%$ & $15.00 \%$ & $3.00 \%$ & $1.00 \%$ & & & & \\
\hline Basel $\rightarrow$ Busto Arsizio & $12 \mathrm{~h}$ & $13 \mathrm{~h}$ & $14 \mathrm{~h}$ & $15 \mathrm{~h}$ & $16 \mathrm{~h}$ & $17 \mathrm{~h}$ & $18 \mathrm{~h}$ & $19 \mathrm{~h}$ \\
$(360 \mathrm{~km})$ & $60.00 \%$ & $16.00 \%$ & $6.00 \%$ & $4.00 \%$ & $3.00 \%$ & $3.00 \%$ & $5.00 \%$ & $3.00 \%$ \\
\hline
\end{tabular}

\section{Appendix A.3. Waterway transportation}

The travel time scenarios for waterway transportation are based on the waterway distances obtained by The Blue Road Map (Bureau Voorlichting Binnenvaart, 2020) and the minimum and maximum speeds of respectively 9 and $11 \mathrm{~km} / \mathrm{h}$ (MarineTraffic, 2020). The assumption of uniformly distributed travel times was suggested by Demir et al. (2017) in case there is insufficient information about the travel time distribution.

\begin{tabular}{ccccccccc}
\hline Corridor & \multicolumn{7}{c}{ Travel time scenario and probability } \\
\hline \hline Rotterdam $\rightarrow$ Mannheim & $55 \mathrm{~h}$ & $56 \mathrm{~h}$ & $57 \mathrm{~h}$ & $58 \mathrm{~h}$ & $59 \mathrm{~h}$ & $60 \mathrm{~h}$ & $61 \mathrm{~h}$ & $62 \mathrm{~h}$ \\
$(600 \mathrm{~km})$ & $7.70 \%$ & $7.70 \%$ & $7.70 \%$ & $7.69 \%$ & $7.69 \%$ & $7.69 \%$ & $7.69 \%$ & $7.69 \%$ \\
& $63 \mathrm{~h}$ & $64 \mathrm{~h}$ & $65 \mathrm{~h}$ & $66 \mathrm{~h}$ & $67 \mathrm{~h}$ & & & \\
& $7.69 \%$ & $7.69 \%$ & $7.69 \%$ & $7.69 \%$ & $7.69 \%$ & & \\
\hline Mannheim $\rightarrow$ Basel & $24 \mathrm{~h}$ & $25 \mathrm{~h}$ & $26 \mathrm{~h}$ & $27 \mathrm{~h}$ & $28 \mathrm{~h}$ & $29 \mathrm{~h}$ & \\
$(260 \mathrm{~km})$ & $16.67 \%$ & $16.67 \%$ & $16.67 \%$ & $16.67 \%$ & $16.66 \%$ & $16.66 \%$ & \\
\hline
\end{tabular}




\section{Appendix B. Punctuality analysis}

Appendix B.1. Example of the high-and low-punctuality case distributions

For our experiment in Section 4.2.3, we assume the same travel time scenarios as in Appendix A In the base case, travel time probabilities are uniformly distributed. The high-punctuality (low-punctuality) case is defined by a symmetrical beta-binomial distribution with a $50 \%$ lower (higher) variance compared to the base case. We demonstrate this approach and provide the probability distributions of the high- and low-punctuality case for the rail service between Rotterdam and Mannheim (570km). We assume the same travel time scenarios for this service as in Appendix A.2. The base case is defined as a uniform distribution, thus each of the eight travel time scenarios has probability $12.5 \%$. The variance of this uniformly distributed base case is 5.25 .

\section{Appendix B.1.1. High-punctuality case}

The high-punctuality case is defined by a symmetrical bell-shaped beta-binomial distribution $(\alpha=\beta>1)$ with a variance of 2.625 , which is $50 \%$ lower compared to the variance of the base case. The travel time probabilities correspond to the bell-shaped distribution shown in Figure B.7

\begin{tabular}{ccccccccc}
\hline Corridor (rail) & \multicolumn{7}{c}{ Travel time scenario and probability } \\
\hline \hline Rotterdam $\rightarrow$ Mannheim & $19 \mathrm{~h}$ & $20 \mathrm{~h}$ & $21 \mathrm{~h}$ & $22 \mathrm{~h}$ & $23 \mathrm{~h}$ & $24 \mathrm{~h}$ & $25 \mathrm{~h}$ & $26 \mathrm{~h}$ \\
$(570 \mathrm{~km})$ & $2.67 \%$ & $8.93 \%$ & $16.58 \%$ & $21.82 \%$ & $21.82 \%$ & $16.58 \%$ & $8.93 \%$ & $2.67 \%$ \\
\hline
\end{tabular}

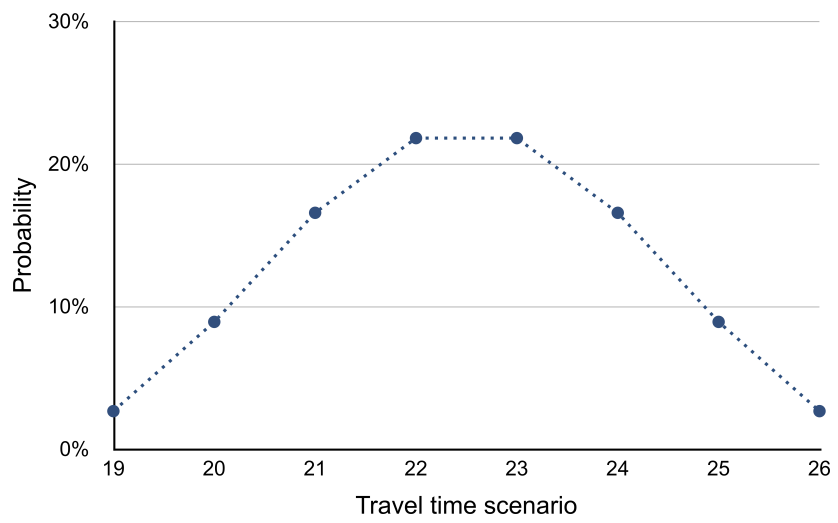

Figure B.7: Probability distribution for the high-punctuality case. 
Appendix B.1.2. Low-punctuality case

The low-punctuality case is defined by a symmetrical U-shaped beta-binomial distribution $(1>\alpha=\beta>0)$ with a variance of 7.875 , which is $50 \%$ higher compared to the variance of the base case. The travel time probabilities correspond to the U-shaped distribution shown in Figure B.8.

\begin{tabular}{ccccccccc}
\hline Corridor (rail) & \multicolumn{7}{c}{ Travel time scenario and probability } \\
\hline \hline Rotterdam $\rightarrow$ Mannheim & $19 \mathrm{~h}$ & $20 \mathrm{~h}$ & $21 \mathrm{~h}$ & $22 \mathrm{~h}$ & $23 \mathrm{~h}$ & $24 \mathrm{~h}$ & $25 \mathrm{~h}$ & $26 \mathrm{~h}$ \\
$(570 \mathrm{~km})$ & $25.49 \%$ & $10.02 \%$ & $7.62 \%$ & $6.87 \%$ & $6.87 \%$ & $7.62 \%$ & $10.02 \%$ & $25.49 \%$ \\
\hline
\end{tabular}

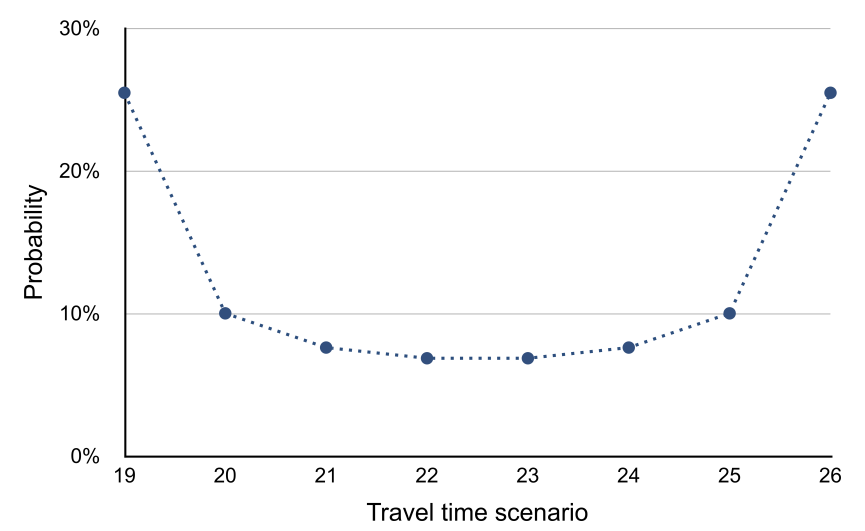

Figure B.8: Probability distribution for the low-punctuality case. 
Appendix B.2. Results

Figure B.9 displays the results of the punctuality analysis for road (top left), rail (top right) and inland waterway (bottom left) transportation, as well as the punctuality analysis for all transportation modes simultaneously (bottom right). We observe that our results remain robust with respect to the degree of punctuality, with at most a one percent difference in cost reduction compared to unimodal road transportation.
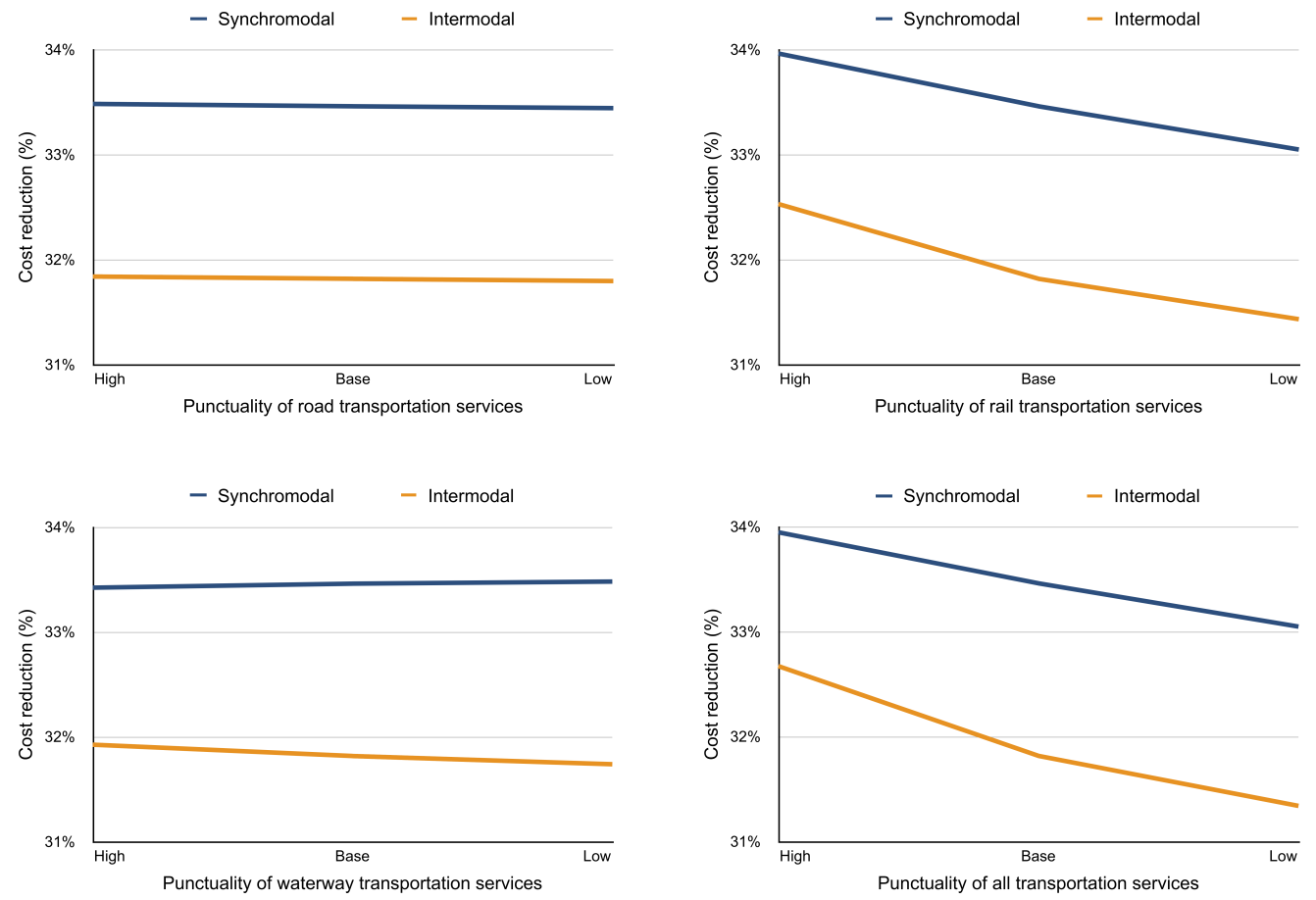

Figure B.9: Sensitivity analysis on the punctuality of the transportation services. The graphs show the cost reductions of synchromodal and intermodal transportation compared to unimodal road transportation. 